\title{
Numerical Optimization of Structures SAW Gas Sensors
}

\author{
T. HEJCZYK ${ }^{a}$, AND M. URBAŃCZYK \\ ${ }^{a}$ ENTE Sp. z o.o., A. Gaudiego 1, 44-100 Gliwice, Poland
}

${ }^{b}$ Faculty of Electrical Engineering, Silesian University of Technology, B. Krzywoustego 2, 44-100 Gliwice, Poland

\begin{abstract}
This paper presents the results of the analysis of surface acoustic waves sensor equivalent model. They were the sensor response of the surface acoustic waves sensor in the steady state gas: $\mathrm{H}_{2}, \mathrm{CO}_{2}, \mathrm{NO}_{2}, \mathrm{NH}_{3}, \mathrm{C}_{n} \mathrm{H}_{m}$, CO. Thin layer of $\mathrm{WO}_{3}$ has been used as a sensor layer. Impedance replacement of sensor layer, taking into account the profile of the concentration of gas molecules in the layer, has been implemented into the equation of Ingebrigtsen, which enabled us to obtain analytical expressions for the relative changes in surface wave velocity in the steady state. The results of the analysis show that there is an optimum thickness of layer sensor for which an acoustoelectric effect (change in the acoustic wave velocity) is the highest.
\end{abstract}

DOI: $10.12693 /$ APhysPolA.124.432

PACS: 43.25.Fe, 77.65.Dq, 68.35.Iv, 07.07.Df

\section{Introduction}

In the past decades, intensive research was conducted on the practical application of the surface acoustic wave (SAW) sensor techniques. The research is conducted in many research centres in Poland, including the Silesian University of Technology, Military University of Technology, Wrocław University of Technology, AGH University in Kraków, and Warsaw University of Technology. There are also well-known design solutions to SAW gas sensors, for example, the company offers commercial solutions to poison gas sensors of American companies, Z-Nose's Sandia National Laboratories, USA, poison gas sensor of HAZMATCAD American company, a commercial solution of VaporLab USA, and others. Generally, these sensors have a very high sensitivity, much higher than the commercially available resistance gas sensors.

Sensor surface acoustic wave is widely used in many industries, especially in biochemical applications, allowing for monitoring of DNA mutation and commercial applications, such as monitoring the quality of food, as well as to monitor the physical and chemical properties of solids, such as adsorption/desorption of the substance, humidity [1-10].

\section{Numerical analysis of the SAW sensor response on gases$$
\mathrm{H}_{2}, \mathrm{CO}_{2}, \mathrm{NO}_{2}, \mathrm{NH}_{3}, \mathrm{C}_{n} \mathrm{H}_{m}, \mathrm{CO}
$$

The acoustoelectric interaction of the surface wave with a charge carriers distributed in a sensor layer, according to the profile resulting from the diffusion of gas molecules from the surrounding atmosphere, analysed numerically in the Python programming environment, using the expression for the calculation of the relative changes in SAW velocity due to the acoustoelectric interaction in sensor layer by use of the analytical model based on the Ingebrigtsen formula [11-13]:

$$
\frac{\Delta v}{v_{0}}=-\operatorname{Re}\left(\frac{\Delta k}{k_{0}}\right)=-\frac{K^{2}}{2}
$$

$$
\begin{aligned}
& \times\left[\sigma_{0}\left(1+a C_{\mathrm{A}, y=0}\right)+\sum_{i=1}^{n-1} \sigma\left(y_{i}\right) f\left(y_{i}, \sigma\left(y_{i}\right)\right)\right]^{2} \\
& /\left\{\left[\sigma_{0}\left(1+a C_{\mathrm{A}, y=0}\right)+\sum_{i=1}^{n-1} \sigma\left(y_{i}\right) f\left(y_{i}, \sigma\left(y_{i}\right)\right)\right]^{2}\right. \\
& \left.+\left[1+\sum_{i=1}^{n-1} g\left(y_{i}, \sigma\left(y_{i}\right)\right)\right]^{2}\left(v_{0} C_{\mathrm{S}}\right)^{2}\right\},
\end{aligned}
$$

where: $i=1,2,3, \ldots n$ (the sublayers index, see Fig. 1), wherein the profile is determined during [4]:

$$
C_{\mathrm{A}}\left(y_{i}\right)=C_{\mathrm{A}, \mathrm{S}} \frac{\cosh \left(y_{i} \sqrt{k / D_{\mathrm{K}}}\right)}{\cosh \left(H \sqrt{k / D_{\mathrm{K}}}\right)}
$$

and $\sigma\left(y_{i}\right)=\sigma_{0}\left[1+a C_{\mathrm{A}}\left(y_{i}\right)\right], a-$ coefficient of sensitivity of a sensor layer $[1 / \mathrm{ppm}]$.

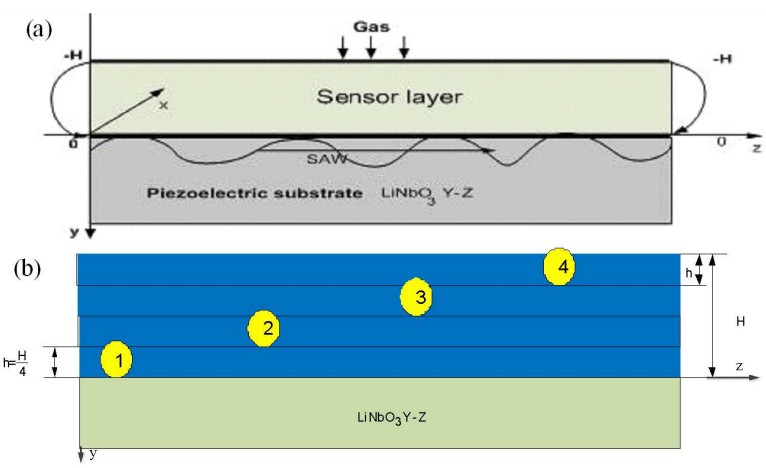

Fig. 1. Model (a) and the equivalent model (b) of the analysed multilayer structure of a sensor [14].

In the expression (1) the functions $f(2)$ and $g(3)$ are the result of the transformation of individual sublayer on the surface of a sensor waveguide (Fig. 1) and has the form

$$
f\left(y_{i}, \sigma_{s}\right)=\frac{1-\left[\tanh \left(k y_{i}\right)\right]^{2}}{\left[1+\tanh \left(k y_{i}\right)\right]^{2}+\left[\tanh \left(k y_{i}\right) \frac{\sigma_{s}}{\varepsilon_{0} v_{0}}\right]^{2}}
$$


and

$$
g\left(y_{i}, \sigma_{s}\right)=\frac{\left[1+\tanh \left(k y_{i}\right)\right]^{2}+\tanh \left(k y_{i}\right)\left(\frac{\sigma_{s}}{\varepsilon_{0} v_{0}}\right)^{2}}{\left[1+\tanh \left(k y_{i}\right)\right]^{2}+\left[\tanh \left(k y_{i}\right) \frac{\sigma_{s}}{\varepsilon_{0} v_{0}}\right]^{2}} .
$$

Conductivity of the semiconductive layer of sensor depends on the temperature

$$
\sigma_{T_{2}}=\sigma_{T_{1}} \exp \left(\frac{E_{\mathrm{g}}}{2 k_{\mathrm{B}}} \frac{T_{2}-T_{1}}{T_{1} T_{2}}\right)
$$

where $\sigma_{T_{1}}$ and $\sigma_{T_{2}}$ are the conductance of the layer, respectively, at temperatures $T_{1}$ and $T_{2}, k_{\mathrm{B}}$ - the Boltzmann constant, $E_{\mathrm{g}}$ - the width of the energy gap of sensor layer material.

The results of numerical analysis can be the basis for the optimization of the layer for maximum sensitivity of the sensor. The following are the results of the numerical analysis for a selected gas, such as $\mathrm{CO}$ or a group of gases, such as $\mathrm{H}_{2}, \mathrm{CO}_{2}, \mathrm{NO}_{2}, \mathrm{NH}_{3}$ [14] and $\mathrm{C}_{n} \mathrm{H}_{m}$ [15] with different concentrations in synthetic air. These gases differ in values of molar masses. Analyses were performed for CO gas for steady-state concentration of gas in a sensor layer $(t \rightarrow \infty)$. The analyses can be carried out also for a short time of a sensor layer interaction with the gas using Eq. (2.5) [16] or using a method based on developing solutions in the Fourier series [13] and the finite element method [11].

$$
\begin{gathered}
C_{\mathrm{A}}\left(y_{i}, t\right)=C_{\mathrm{A}, \mathrm{S}}\left[1-\frac{2}{\pi} \sum_{n=1}^{\infty} \frac{1-(-1)^{n}}{n}\left[\exp \left(-\omega_{n}^{2} t\right)\right.\right. \\
\left.\left.+\frac{k\left[1-\left(1+\omega_{n}^{2} t\right) \exp \left(-\omega_{n}^{2} t\right)\right]}{\omega_{n}^{2}+k\left(1-\exp \left(-\omega_{n}^{2} t\right)\right)}\right] \sin \frac{n \pi\left(H-y_{i}\right)}{2 H}\right],
\end{gathered}
$$

where $\omega_{n}=\frac{n \pi \sqrt{D_{\mathrm{K}}}}{2 H}, C_{\mathrm{A}, \mathrm{S}}$ is the gas concentration at the surface of the layer $(y=-H), H-$ a sensor layer thickness, $n$ - here the number of iterations.

As assumed, $\mathrm{WO}_{3}$ (tungsten dioxide) was often used as a sensor layer to detect hydrogen and hydrocarbon. For comparative purposes sensor oxide $\mathrm{NiO}, \mathrm{TiO}_{2}$ and $\mathrm{SnO}_{2}$ layers were also analysed. The results of numerical calculations performed for the sensor with a layer of $\mathrm{WO}_{3}$ for hydrogen have been verified experimentally $[15,16]$.

In SAW sensors a relative change in surface wave velocity is taken as the response of the sensor. This change has a direct bearing on the relative changes in the oscillation frequency of the sensor system with the acoustic delay line in the feedback loop amplifier. The frequencies of the basic differential sensor system with two oscillators (measurement and reference) are presented below.

Presented in Fig. 2 results of the analysis can be seen that there is an optimum thickness for which a sensor acoustoelectric effect (change in the acoustic wave velocity) is the largest [11]. Qualitatively, the existence of an optimal thickness of a sensor $\left(\mathrm{WO}_{3}\right)$ was confirmed experimentally in the studies presented in [12]. The answer of a layer that is too thin (less than about $50 \mathrm{~nm}$ ) is small, which is associated with the effect of rapid saturation of a thin layer of gas molecules with a low concentration. In

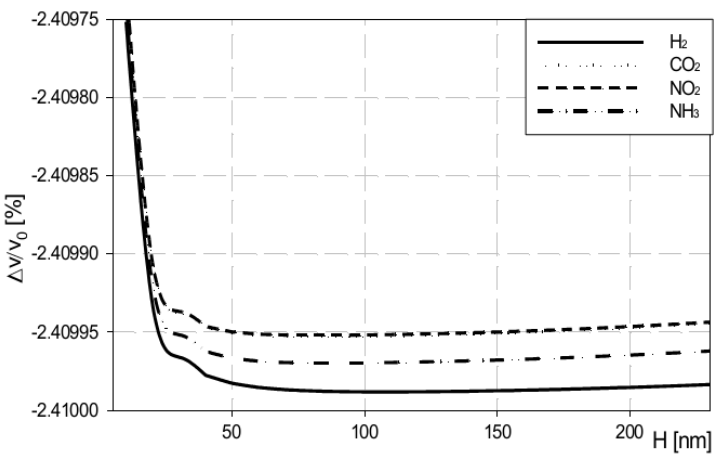

Fig. 2. Effect of $\mathrm{WO}_{3}$ film thicknesses on a sensor surface wave velocity changes for gas $\mathrm{H}_{2}, \mathrm{CO}_{2}, \mathrm{NO}_{2}$, and $\mathrm{NH}_{3}$ concentration $1000 \mathrm{ppm}$. Calculations were performed for $a=0.17 \mathrm{ppm}^{-1}$, temperature $320 \mathrm{~K}$, the pore radius of $2 \mathrm{~nm}$.

too thick layer the diffusion of gas molecules causes their nonuniform distribution in the layer, and the maximum concentration (although fairly flat) will be moved away from the waveguide. Effect of film thickness on the size of the sensor response is relatively small beyond a certain thickness of the layer - a relatively flat time curve (Figs. 2 and 3) (for the case with thicknesses greater than about $100 \mathrm{~nm}$ ).

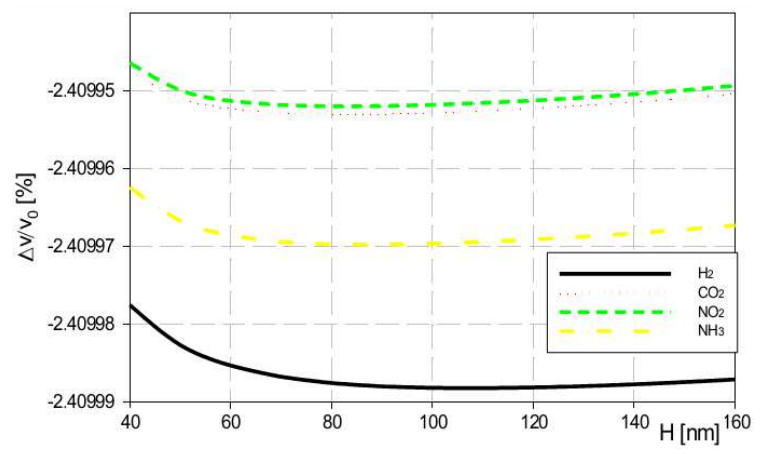

Fig. 3. The dependence of the propagation speed changes on the thickness of the $\mathrm{WO}_{3}$ concentration of $1000 \mathrm{ppm}$ for $\mathrm{H}_{2}, \mathrm{CO}_{2}, \mathrm{NO}_{2}$, and $\mathrm{NH}_{3}$. The pore radius $r=2 \mathrm{~nm}, T=350 \mathrm{~K}, a=0.17 \mathrm{ppm}^{-1}$. Zoom in interesting tile thickness of about $40 \mathrm{~nm}$ to $160 \mathrm{~nm}$.

Figure 3 shows an enlargement of interesting changes in the thickness range of a sensor. You can see the characteristics of a fairly broad plateau. The layer thickness ranges from about 80 to $140 \mathrm{~nm}$, the sensor response (expressed by the relative change in acoustic wave propagation velocity) is almost independent of its thickness. Location graphs for each of the gases is dependent on the type of gas molecules (on its size, molecular weight). In the case of hydrogen, the molecule with the lowest molecular weight, changes in the wave propagation velocity are greatest (lowermost curve), whereas in the case of carbon dioxide and nitrogen dioxide, there are the smallest 
changes in speed (the two curves located at the highest - Fig. 3). This result is consistent with intuition - the particles with a lower molar mass in the layer of predetermined porosity diffuse more easily, reaching areas located deeper in the layer of a sensor, which is of crucial importance for the mechanism of acoustoelectric interaction.

Gases of great importance in industry and environmental protection are hydrocarbons with the general chemical formula $\mathrm{C}_{n} \mathrm{H}_{m}$. This group includes, among others methane, ethane, propane, and benzene [12]. Tungsten dioxide as a single sensor layer or in combination with a palladium catalyst can be used to detect these hydrocarbons. This section gives a response of sensor cover with a layer of $\mathrm{WO}_{3}$ to the selected group of hydrocarbons.

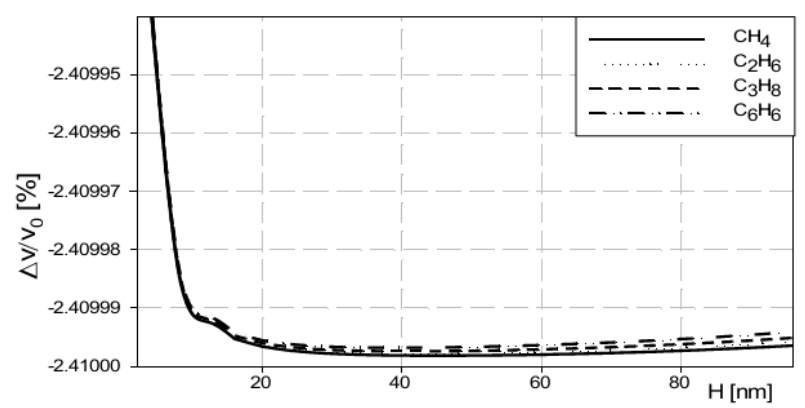

Fig. 4. Effect of film thickness on a sensor surface wave velocity changes for molecules $\mathrm{CH}_{4}, \mathrm{C}_{2} \mathrm{H}_{4}, \mathrm{C}_{3} \mathrm{H}_{8}, \mathrm{C}_{6} \mathrm{H}_{6}$. Calculations were performed for $a=0.17 \mathrm{ppm}^{-1}$, temperature $350 \mathrm{~K}$, the pore radius of $2 \mathrm{~nm}$, a layer of $\mathrm{WO}_{3}$ $\left(E_{\mathrm{g}}=2.7 \mathrm{eV}\right)$.

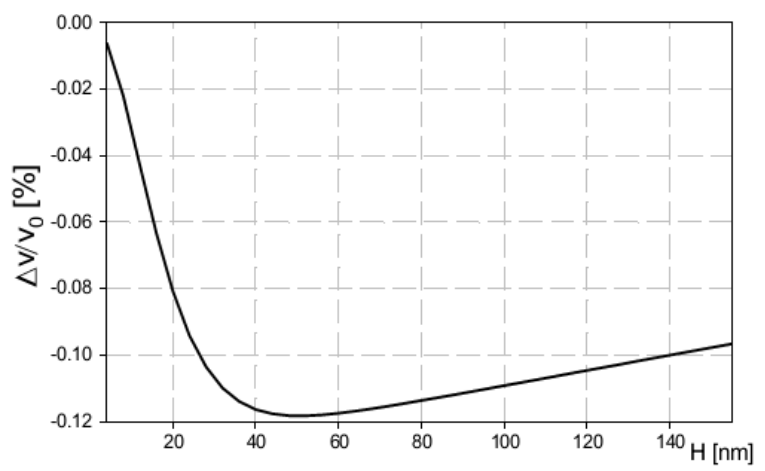

Fig. 5. Sensor responses to $\mathrm{CO}$ concentration of $100 \mathrm{ppm}$ in synthetic air as a function of sensor $\mathrm{WO}_{3}$ film thickness at $40^{\circ} \mathrm{C}$. The analysis was based on: a sensitivity factor $a=0.5 \mathrm{ppm}^{-1}$, the conductivity of the surface layer of $4.7 \times 10^{-7} \mathrm{~S}, k=10^{8} \mathrm{~s}^{-1}$, $D_{\mathrm{K}}=10^{12} \mathrm{~nm}^{2} \mathrm{~s}^{-1}, E_{\mathrm{g}}=2.7 \mathrm{eV}, M=28 \mathrm{~g} / \mathrm{mol}(\mathrm{CO})$.

The answer to a sensor layer, also in this case, the thickness is affected. In the case of hydrocarbon groups optimum layer thickness ranges from 30 to $40 \mathrm{~nm}$ [8] (Fig. 4) and is smaller than the molecules of $\mathrm{H}_{2}, \mathrm{CO}_{2}$, $\mathrm{CO}, \mathrm{NO}_{2}$, and $\mathrm{NH}_{3}$ (Fig. 2 and Fig. 3). For this group of gases optimum thickness was about 60 to $80 \mathrm{~nm}$ (Fig. 5). This difference can be explained by the much larger size of the hydrocarbon molecules. Diffusion of large molecules is difficult and thicker layers of saturation do not occur throughout the volume of the layer. The electrical conductivity of the deeper layers does not change, so their contribution to the sensor response will be small.

\section{Summary}

Assuming a Knudsen diffusion mechanism of gas particles in a porous layer of a sensor determined concentration profiles of gas molecules in the layer in steady state characteristics (sensor response dependence on the thickness of the layer) gas: $\mathrm{H}_{2}, \mathrm{CO}_{2}, \mathrm{NO}_{2}, \mathrm{NH}_{3}$, methane, ethane, propane, benzene $\left(\mathrm{CH}_{4}, \mathrm{C}_{2} \mathrm{H}_{4}, \mathrm{C}_{3} \mathrm{H}_{8}, \mathrm{C}_{6} \mathrm{H}_{6}\right)$, and $\mathrm{CO}$. Extensive numerical analyses of the sensor response parameter thickness were conducted. Analytical studies were carried out for the steady state. Numerical analyses were performed using proprietary software written in Python.

The optimum thickness of a sensor depends on the porosity of the layer and a type (size) of gas molecules diffusing into the interior. Detailed analysis of the optimal thickness of $\mathrm{WO}_{3}$ for hydrogen molecules is about 90$100 \mathrm{~nm}[14,15]$. Hydrogen molecules are much smaller than the molecules of methane and carbon monoxide (in the case of the molecular weight of hydrogen is $2 \mathrm{~g} / \mathrm{mol}$, while the methane $16 \mathrm{~g} / \mathrm{mol}$, carbon monoxide $28 \mathrm{~g} / \mathrm{mol}$ ), hence the difference in the diffusion taking place in the layer. The concentration profile of the gas molecules and the associated electric charge distribution in the layer of a sensor will be different for different types of gas. At the same porosity layer sensor response to molecules of higher molecular weight are greater for thinner layers, which can be observed in the experiment, and as confirmed by the results of numerical analyses sensor based on the model proposed in the thesis. The layer thickness will affect the maximum range of gas concentrations. Thicker layers will be useful for applications at higher gas concentrations (saturation occurs as response of gas at higher concentrations). Also the choice of the temperature of the sensor is important, which will depend on the type of sensor layer and its porosity. The change allows you to set the temperature of the sensor [14-16], and also has an impact on the speed of response and recovery of sensor layer. Diffusion phenomena which are responsible for the dynamics of the sensor response depend on the temperature of a sensor layer. The results of numerical analysis, written in Python show that the optimum thickness of the layers for the interaction of $\mathrm{CO}$ gas sensor cover with a layer of a thickness of about $50 \mathrm{~nm}$, which coincides with the results of the experiment.

\section{Acknowledgments}

The work is financed by the NCBiR within the grant No. OR00017912. 


\section{References}

[1] K. Jasek, S. Neffe, M. Pasternak, Acta Phys. Pol. A 122, 825 (2012).

[2] T. Pustelny, A. Opilski, B. Pustelny, Acta Phys. Pol. A 114, A-183 (2008).

[3] A. Kawalec, M. Pasternak, K. Jasek, Eur. Phys. J. Spec. Top. 154, 123 (2008).

[4] M. Urbańczyk, Sensors with Surface Acoustic Wave - Monograph, Vol. 213, SUT, Gliwice 2011 (in Polish).

[5] T. Pustelny, J. Ignac-Nowicka, Z. Opilski, Opt. Appl. 34, 563 (2004).

[6] K. Jasek, W. Miluski, M. Pasternak, Acta Phys. Pol. A 120, 638 (2011).

[7] P. Struk, T. Pustelny, K. Gut, K. Golaszewska, E. Kaminska, M. Ekielski, I. Pasternak, E. Lusakowska, A. Piotrowska, Acta Phys. Pol. A 116, 414 (2009).

[8] T. Pustelny, J. Ignac-Nowicka, Z. Opilski, Opt. Appl. 34, 249 (2004).
[9] T. Pustelny, M. Grabka, Acta Phys. Pol. A 116, 385 (2009).

[10] B. Pustelny, T. Pustelny, Acta Phys. Pol. A 116, 383 (2009).

[11] F. Byron, R. Fuller, Mathematics in Classical and Quantum Physics, Vol. I, PWN, Warsaw 1973 (in Polish).

[12] T. Hejczyk, M. Urbańczyk, Acta Phys. Pol. A $\mathbf{1 2 0}$, 798 (2011)

[13] T. Hejczyk, M. Urbańczyk, R. Witula, E. Maciak, Bull. Pol. Acad. Sci., Techn. Sci. 60, 589 (2012).

[14] T. Hejczyk, M. Urbańczyk, W.P. Jakubik, Acta Phys. Pol. A 118, 1158 (2010).

[15] W. Jakubik, M. Urbańczyk, E. Maciak, T. Pustelny, Bull. Pol. Acad. Sci., Techn. Sci. 56, 133 (2008).

[16] T. Hejczyk, M. Urbańczyk, Acta Phys. Pol. A 120, 616 (2011). 